\section{A Autoimunidade Extra-Pancreática no DMI: Pesquisando Também Doença Celíaca}

$\mathrm{H}$ Á ALGUMAS DÉCADAS sabe-se que o diabetes mellitus do tipo l (DMl) é uma doença de origem autoimune. A auto-imunidade contra as células $\beta$ pode ser gerada por diferentes auto-antígenos e está associada freqüentemente à auto-imunidade contra outros antígenos extrapancreáticos. As síndromes poliglandulares autoimunes - SPA I e II -, a associação com doença celíaca (DC) e com tireoidite linfocítica crônica são alguns exemplos de que a desordem de tolerância imunológica pode ser mais geral do que específica contra as células $\beta$ (1). $\mathrm{O}$ aparecimento seqüencial de auto-anticorpos contra mais de um órgão sugere ainda uma ativação independente das diferentes desordens autoimunes. Acredita-se que estes fenômenos devam estar associados a tipos específicos de HLA, como no caso da doença celíaca (HLA DQAl *0501-DQBl *0201+) (2), além dos fatores ambientais como vírus.

O estudo publicado neste número dos ABE\&M por Brandt, Silva e Antunes (3) aponta para uma prevalência de $15,3 \%$ de DC em pacientes diabéticos brasileiros. Estudos internacionais mostram uma prevalência variável, com média de 4,5\% (0,97 a 16,4\%) em uma análise de 26 publicações (4). Não sabemos se esta elevada prevalência encontrada no estudo nacional explica-se por alguma característica específica da população brasileira, ou por ter sido avaliada uma amostra $(n=19)$ do total de pacientes acompanhados naquela instituição $(n=150)$. Contribuindo com esta discussão, recente publicação de Whitacker e cols (5) encontrou em 178 crianças e adolescentes com DMl na região de Campinas (SP) uma prevalência de $2,8 \%$ de DC. Há, portanto, que se confirmar esta prevalência com estudos nacionais mais abrangentes.

Além da prevalência, outros dados devem ser analisados em estudos desta natureza, como a associação com outras doenças autoimunes (tireoidite), idade dos pacientes, tempo de diagnóstico de DM e a existência de familiares com doenças autoimunes. A melhor caracterização deste grupo poderia facilitar o encontro de fatores de risco para o desenvolvimento da DC em pacientes com DMl em nosso meio.

É interessante notar que a presença de sinais de DC, previamente ao diagnóstico, é geralmente pouco relatada. Os pacientes podem não apresentar queixas ou estas podem ser vagas e inespecíficas, não sendo percebidas pelo médico. Neste estudo foram encontrados sintomas sugestivos em 3 dos 4 pacientes apenas após a confirmação diagnóstica. Isto deve servir de alerta, para que sintomas como distensão ou dor abdominal, mesmo sem outros comemorativos, sejam valorizados, uma vez que possibilitariam um diagnóstico mais precoce.

Existe ainda algum questionamento sobre o benefício real do diagnóstico e tratamento dietético da DC na população de diabéticos assintomáticos, já que a introdução de uma nova dieta geralmente não é de fácil aceitação pelo paciente e familiares. Acompanhamentos a longo prazo de pacientes com DMl e DC sugerem que após a introdução da dieta sem glúten ocorre melhora dos sintomas abdominais, recuperação do peso para editorial

\author{
Luis Eduardo P. Calliari
}

Unidade de Endocrinologia Pediátrica do Departamento de Pediatria, Faculdade de Ciências Médicas da Santa Casa de São Paulo, SP. Presidente do Departamento de Endocrinologia da Sociedade de Pediatria de São Paulo. 
a altura e do índice de massa corporal, bem como modificações do padrão de controle metabólico (6).

$\mathrm{O}$ trabalho publicado neste número dos ABE\&M (3) tem o mérito de chamar a atenção para esta importante associação, de DMl com doença celíaca, que deveria ser mais valorizada no acompanhamento rotineiro dos pacientes diabéticos. A realização de estudos multicêntricos também seria de suma importância, devido ao pequeno número de pacientes acometidos, já que permitiria uma maior compreensão do panorama desta associação no Brasil.

\section{REFERÊNCIAS}

1. Calliari LEP. Diabetes mellitus e doenças autoimunes correlatas. Arq Bras Endocrinol Metab 2003;47/2(supl. 1):S33S34.

2. De Block CEM, De Leeuw IH, Vertommen JJF, Rooman $\mathrm{RPA}$, et al, and the Belgian Diabetes Registry Group. Beta-cell, thyroid, gastric, adrenal and coeliac autoim- munity and HLA-DQ types in type 1 diabetes. Clin Exp Immunol 2001;126/2:236-44.

3. Brandt KG, Silva GAP, Antunes MMC. Doença celíaca em um grupo de crianças e adolescentes portadores de diabetes mellitus tipo 1. Arq Bras Endocrinol Metab 2004;48/6:-

4. Holmes GKT. Screening for coeliac disease in type 1 diabetes. Arch Dis Child 2002;87:495-8.

5. Whitacker FCF, Brunelli MMC, Carvalho AB, Schneider GS, lamada CF, Lemos-Marini SHV, et al. Prevalence of celiac disease in patients with type 1 diabetes mellitus. J Pediatr Endocrinol Metab 2004;17(suppl.5): 1362.

6. Saadah OI, Zacharin M, O'Callaghan A, Oliver MR, Catto-Smith AG. Effect of gluten-free diet and adherence on growth and diabetic control in diabetics with coeliac disease. Arch Dis Child 2004;89(9):871-6.

Endereço para correspondência:

Luis Eduardo P. Calliari

Rua Sergipe 401 - cj. 802

01243-906 São Paulo, SP

E-mail: caliari@uol.com.br 